www.jmscr.igmpublication.org

Impact Factor (SJIF): 6.379

Index Copernicus Value: 79.54

ISSN (e)-2347-176x ISSN (p) 2455-0450

crossrefDOI: https://dx.doi.org/10.18535/jmscr/v6i12.34

Journal Of Medical Science And Clinical Research

IGM Publication

An official Publication of IGM Publication

\title{
A Comparative Study between Endoscope-assisted and Craniotomy Evacuation in Spontaneous Intracerebral Hematoma
}

\author{
Authors \\ Dr Mst. Shamima Sultana', Dr Md. Shafiqul Islam², Dr Md. Sumon Rana ${ }^{3}$, \\ Dr Kanij Fatema Ishrat Zahan Rifat ${ }^{4}$, Dr Monsur Ahmed ${ }^{5}$, Dr Abul Kalam Azad ${ }^{6}$, \\ Prof. Kanak Kanti Barua ${ }^{7}$ \\ ${ }^{1}$ Assistant Registrar, Department of Neurosurgery, Rangpur Medical College and hospital, Rangpur, Bangladesh \\ ${ }^{2}$ Associate Professor, Department of Neurosurgery, Dhaka Medical College and hospital Dhaka, Bangladesh \\ ${ }^{3}$ Medical Officer, Department of Neurosurgery, Dhaka Medical College and hospital Dhaka, Bangladesh \\ ${ }^{4}$ Assistant Professor, Department of Neurosurgery, Dhaka Medical College and hospital Dhaka, Bangladesh \\ ${ }^{5}$ Registrar, Department of Neurosurgery, Dhaka Medical College and hospital Dhaka, Bangladesh \\ ${ }^{6}$ Assistant Professor, Department of Medicine, Rangpur Medical College Hospital, Rangpur, Bangladesh \\ ${ }^{7}$ Vice Chancellor, Bangabandu Sheikh Mujib Medical University, Dhaka, Bangladesh \\ Corresponding Author
}

Dr Mst. Shamima Sultana

Assistant Registrar, Department of Neurosurgery, Rangpur Medical College and hospital, Rangpur, Bangladesh

\section{Abstract}

Introduction: Although, Intracerebral hemorrhage (ICH) accounts for only $10 \%$ to $15 \%$ of all strokes but it is a common disease with an incidence ranging from 11 to 23 cases per 100,000 per year. This study was done to determine and compare the functional outcome of patients with spontaneous intra-cerebral hemorrhage (ICH) by modified Rankin scale $(\mathrm{mRS})$, treated by endoscope-assisted evacuation with that of craniotomy. This study also aims to find out the hematoma evacuation rate, operating time and improvement of Glasgow Coma scale (GCS) in both groups and to compare it.

Materials and Methods: We have studied 40 patients of spontaneous ICH diagnosed by non-contrast CT (Computed Tomography) scan of brain. In 20 patient's endoscope-assisted hematoma evacuation and in another 20 patients craniotomy evacuation was done. Follow up CT scan was done within 24 hrs of surgery to compare with preoperative scan. Data were analyzed by demographic variable (age, sex), clinical (GCS at admission, on 3rd postoperative day and at discharge), radiological (side, location, and volume of hematoma), hematoma evacuation rate and operating time. Follow up was done at 3 months and outcome was measured by modified Rankin scale $(m R S)$.

Results: The mean (SD-Standard Deviation) age of endoscope-assisted group and craniotomy group was found 57.9(9.9) years and 52.2(11.7) years respectively. Male sex was predominant. Hematoma was located in gangliothalamic region in 9(45\%) patients and lobar in 11(55\%) patients in endoscope-assisted group. In 8(40\%) patients hematoma was located in ganglio-thalamic region and 12(60\%) patients in lobar in craniotomy group. Majority of study patients had hematoma on left side. Surgery was done within 48 hrs from the onset of symptoms. Four patients (20\%) were died from endoscope-assisted group and seven patients (35\%) died from craniotomy group. There was no statistically significant difference $(p>0.05)$ between two groups regarding age, sex, location of hematoma, improvement in GCS and mortality rate. Mean operating time was 1.23(0.47) hrs in endoscope-assisted group and $2.15(0.56)$ hrs in craniotomy group. Hematoma evacuation rate was better in endoscope-assisted group 74(11) \% than in craniotomy group $65(13) \%$. There was statistically significant difference regarding operating time, hematoma evacuation rate and outcome in both groups ( $p<0.05)$. 
Conclusion: This study revealed that endoscope-assisted procedure has better outcome and hematoma evacuation rate than craniotomy.

Keywords: Intracerebral hemorrhage, modified Rankin scale, Glasgow Coma scale, Hematoma evacuation rate, endoscope-assisted group.

\section{Introduction}

Intracerebral hemorrhage (ICH) is a common disease with an incidence ranging from 11 to 23 cases per 100,000 per year. Although it accounts for only $10 \%$ to $15 \%$ of all strokes, it is the fatal stroke subtype with mortality up to $40 \% .{ }^{[1]}$ Risk factors include age, hypertension, history of coronary artery disease, previous stroke or TIA, cigarette smoking, alcohol consumption, low serum cholesterol, low dose aspirin and oral contraception. ${ }^{[2]}$

According to etiological aspects primary or spontaneous hemorrhage can be distinguished from secondary hemorrhage. Primary hemorrhages are spontaneous hemorrhages, which are mainly caused by arterial hypertensive diseases. Secondary hemorrhages are due to traumatic, tumorous or pharmacological causes ${ }^{1}$. Cerebral amyloid angiopathy is a common cause of ICH in the elderly, which is not associated with arterial hypertensive disease. $^{[3]}$

Lobar hemorrhage incorporate primary hemorrhages into the occipital, temporal, frontal and parietal lobes (including ICH arising from cortex and sub-cortical white matter), as opposed to hemorrhage of deep structures (e.g. basal ganglion, thalamus and infratentorial structures ). It accounts for 10-32 \% of non-traumatic ICH. With large hemorrhages, it may be difficult to make a distinction between lobar and deep ICH. Lobar hemorrhages may also have a more benign outcome than ganglio-thalamic hemorrhages. ${ }^{[4]}$ Understanding the pathophysiology and the natural history of ICH is of utmost importance as it provides the basis for identifying potential therapeutic targets. ICH results from vessel rupture and blood extravasation in the brain parenchyma, leading to hematoma formation, mechanical disruption and tearing of neighboring blood vessels, leading to growth of the hematoma and culminating in cessation of neuronal function.
This primary insult is followed by a cascade of secondary events including edema formation, precipitated by the growing mass of blood and toxic effects of blood degradation products, over the ensuing days-to-weeks resulting in delayed (secondary) neuronal injury ${ }^{[5]}$. The classic presentation of $\mathrm{ICH}$ is the progressive onset of focal neurological deficits over minutes to hours with accompanying headache, nausea, vomiting, decreased level of consciousness and elevated blood pressure. ${ }^{[6]}$

Computerized tomography offers early and accurate diagnosis of intracerebral hemorrhage. Consequently the differential diagnosis between spontaneous ICH, subarachnoid hemorrhage, cerebral infarction and traumatic ICH has become more reliable and the size and location of ICH can be precisely defined. ${ }^{[7]}$ Several factors influence the extremely poor outcome associated with spontaneous ICH, such as the level of consciousness at presentation, volume of parenchymal hemorrhage, volume of intraventricular hemorrhage (IVH), and the extent of cerebral damage. ${ }^{[8]}$ Hematoma expansion has been identified as one of the most important determinants of early neurological deterioration and poor outcome in primary $\mathrm{ICH} .{ }^{[9]}$

The era of minimally invasive surgical intervention for ICH evacuation started in the late 1980s when Auer et al published a controlled randomized study of endoscopic evacuation vs. medical treatment in 100 patients with spontaneous ICH, and showed that surgical patients with smaller hematomas made a significantly better functional recovery than did patients of the medically treated group (30\% vs. $70 \%, \mathrm{P}<.05)$, and patients with larger hematomas showed significantly lower mortality rates after operation than the medically treated group. ${ }^{[8]}$ The selection of the approach (the frontal and temporal approach) for putaminal ICH is an 
important issue. In patients with ICH volume less than $50 \mathrm{ml}$ it is not difficult to evacuate the hematoma through the shortest distance from the cortical surface to the hematoma. However when the hematoma is larger than $50 \mathrm{ml}$, the shape usually became elliptical .The frontal approach was recommended in these cases due to its involving non-eloquent regions and providing better visualization that may result in maximal hematoma evacuation. ${ }^{[10]}$

Endoscope-assisted ICH evacuation performed in the early stage was associated with a minimal rebleeding rate (0\%-3.3\%) compared with the traditional craniotomy method (5\%-10\%). Other advantages of the endoscope-assisted method include low complication rate, less operative time, less blood loss, improved evacuation rate, and early recovery of the patients. ${ }^{[11]}$

Though the main clinical management of SICH includes surgical and medical treatment, whether patients can benefit from surgery is still controversial, especially those with basal ganglia hemorrhage, which is the major subtype of SICH. ${ }^{[18]}$ The numbers of stroke patients are increasing day by day. Most of them are spontaneous ICH. Late arrival in hospital and poor neurological status sometimes does not permit us to do more time consuming invasive operative procedure in such patients. More recently with the improvements in endoscopic technique ICH has begun to be approached using the technique. So, it is rational to choose minimal invasive endoscopeassisted technique for evacuation of hematoma in patients with spontaneous ICH.

\section{Materials and Methods}

This was a randomized controlled clinical trial (RCT). This study was carried out at the department of Neurosurgery, Dhaka Medical College and Hospital, Dhaka, Bangladesh from January, 2015 to June, 2016. We have studied 40 diagnosed patients of Spontaneous ICH admitted or referred, who fulfill the selection criteria. Variables were patient's age, sex, GCS at admission, on $3^{\text {rd }}$ post-operative day and at discharge, operating time, hematoma evacuation rate and mRS (Modified Rankin Scale) at three months.

Patients with age 30 to $75 \mathrm{yrs}$, GCS 8 to 13 and hematoma volume $>30 \mathrm{ml}$ in ganglio-thalamic region and a subcortical hemorrhage $>30 \mathrm{ml}$ with significant mass effect (midline shift greater than $5 \mathrm{~mm}$, perilesional edema and effacement of ventricles) were included. Patients having GCS $\leq$ 7 and >13 and hematoma volume $>62 \mathrm{ml}$ were excluded from the study. Patients with purely intraventricular hemorrhage and cerebellar hemorrhage also excluded.

For the purpose of study we subdivided GCS into groups: < 8, 8-10, 11-13 and >13. The ABCs method was adopted to measure the hematoma volume: Volume $(\mathrm{ml})=(\mathrm{A} \times \mathrm{B} \times \mathrm{C}) / 2^{12}$. The hematoma evacuation rate was calculated and presented by percentage as: Preoperative hematoma volume (ml)- Post-operative volume/Pre-operative volume ${ }^{13}$. Both group received best available medical treatment along with surgery.

For endoscope-assisted evacuation we used 4mm 0 degree rod-lens endoscope and sheath was prepared from outer covering of 3-cc syringe having inner diameter $10 \mathrm{~mm}$ and length $5.5 \mathrm{~cm}$, proximal end was beveled to prevent brain injury. Sheath was fitted with an obturator having diameter $9 \mathrm{~mm}$.We used sucker nozzle diameter 2-4 $\mathrm{mm}$ as per needed.

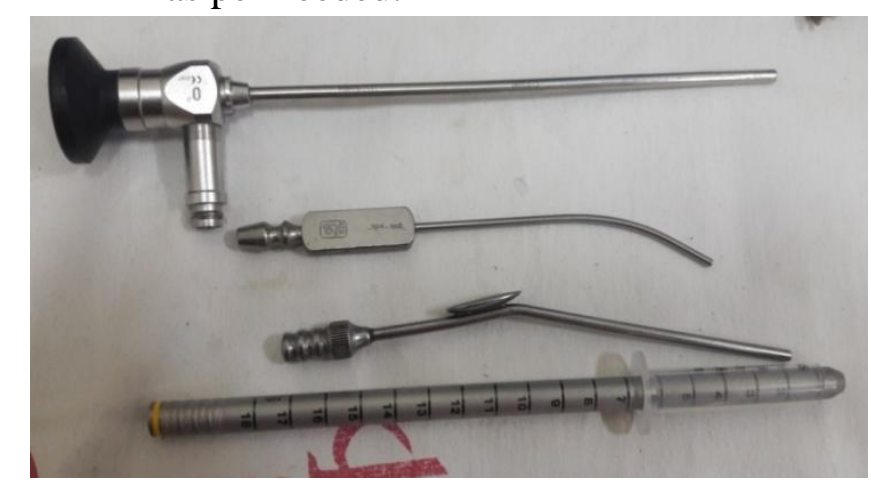

Figure 1: Equipment of endoscope-assisted evacuation (sheath with obturator)

All surgical procedures were performed under general anesthesia. For patients with gangliothalamic ICH either "frontal" or "temporal" approach $^{[14]}$ was used in order to provide the 


\section{JMSCR Vol ||06||Issue||12||Page 212-220||December}

shortest distance between the cortical surface and the hematoma on the preoperative CT scan. In patients with lobar hemorrhage the corridor that traverses the shortest distance to the hematoma (judging from the preoperative CT scan) was used. A linear skin incision (3-4 cm in length) is created. A 1.5 - to $2.0-\mathrm{cm}$ burr hole ${ }^{[10]}$ is then created with the dura opened as a U-shaped flap. ${ }^{[15]}$

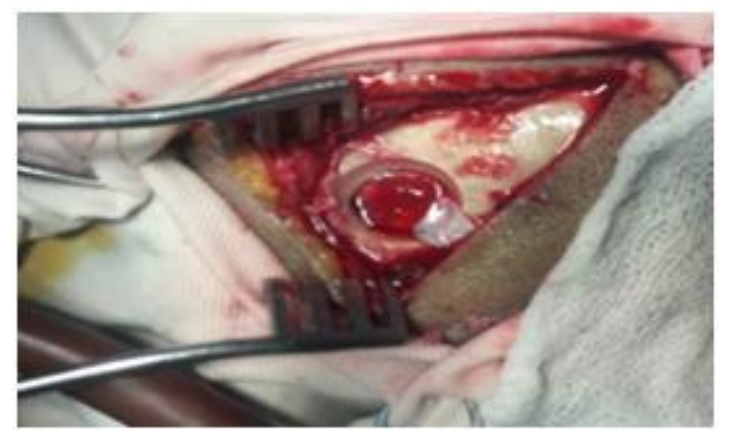

Figure 2: Burr hole and U-shaped flap of dura

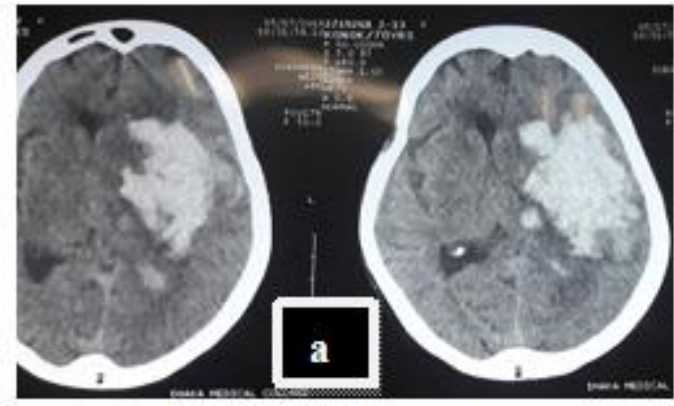

Figu re 3: Pre-operativeview (a) and post-operative view (b) in endoscope assisted evacuation

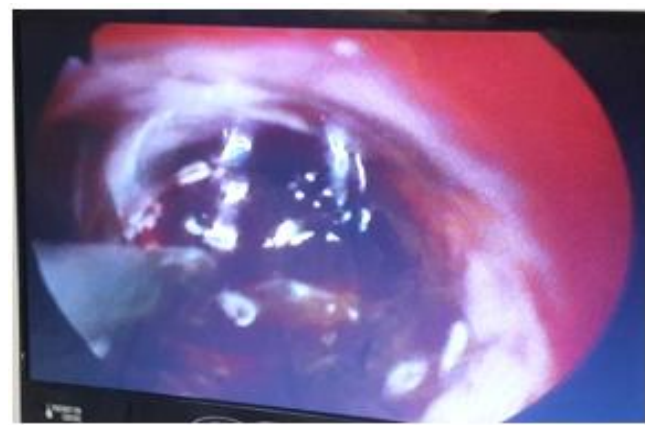

Figure 4: Endoscopic view of hematoma

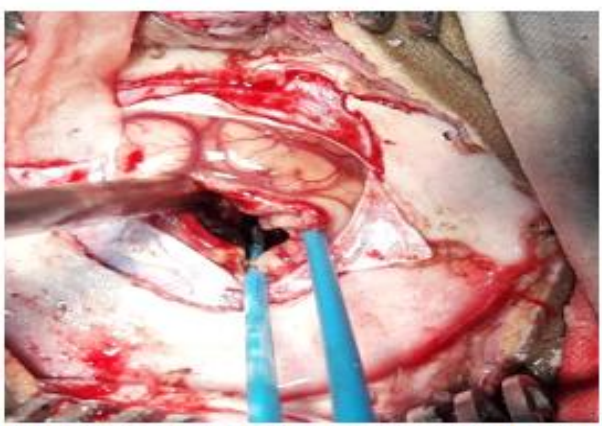

Figure 6: Craniotomy and evacuation
With a small corticotomy or trans-sulcus we introduced obturator loaded sheath down to the depth measured by brain cannula and length estimated from the preoperative CT scan up to entry into the clot cavity. The most distal part of the hematoma was evacuated first by help of sucker and as the sheath is gradually withdrawn the residual hematoma pushed into the tip of the sheath as the brain expands. The hematoma is evacuated by manipulating the suction through the working space within the sheath. ${ }^{[10]}$ Orientation was that the telescope up and sucker nozzle down for aerial view.

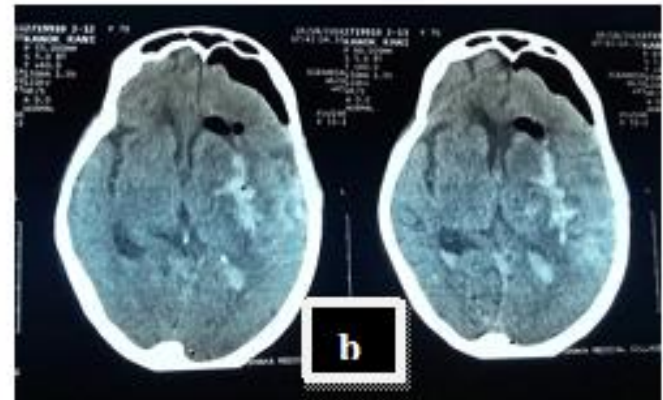

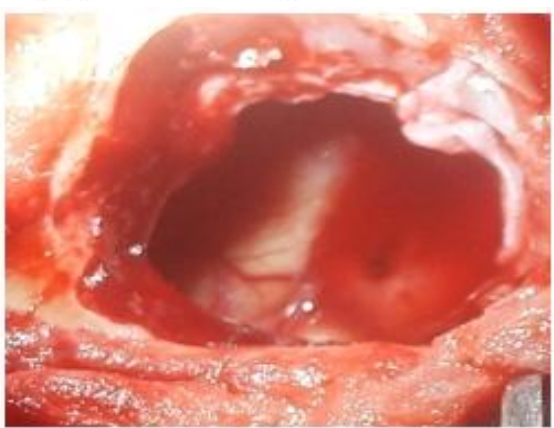

Figure 5: Hematoma cavity

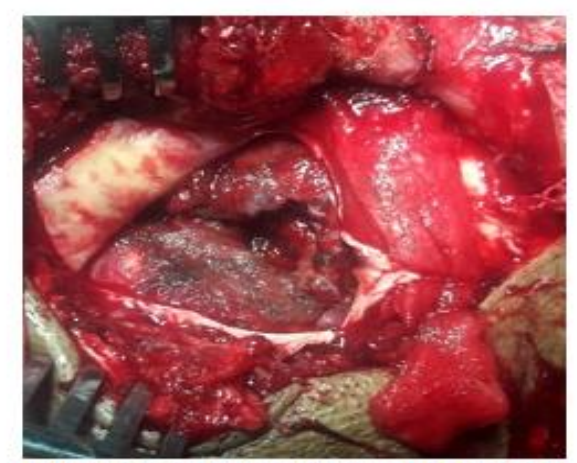

Figure 7: Trans-sylvian evacu ation 
In craniotomy group pterional craniotomy was done in ganglio-thalamic ICH and by transsylvian dissection hematoma was evacuated. In case of lobar hematoma craniotomy done after brain mapping over the preferred site. Dura was opened by circulate incision. Hematoma was evacuated with suction equipment.

\section{Results}

Table 1 shows age limit was 30 to 75 years no patient found in the study below 34 years. There is no statistical significant difference in age distribution among both groups ( $\mathrm{p}>0.05)$. Table 2 shows, there was male predominance with $75 \%$ in the endoscope-assisted group with $80 \%$ in the craniotomy group .No statistically significant difference was observed. Table 3 shows GCS nineteen 19 (95\%) patients from endoscopeassisted group and 18 (90\%) patients from craniotomy group were GCS in between 8-10 in pre-operative period. GCS improved to $11-13$ in 8 (40\%) patients and >13 in $5(25 \%)$ patients in endoscope-assisted group. In craniotomy group 9 (52.9\%) patients were in GCS 11-13 and 1(5.9\%) patients in GCS >13. At discharge 10 (62.5\%) patients in endoscope-assisted group and 5 (38.5\%) patients in craniotomy group had GCS $>13$.No statistically significant difference observed regarding GCS between two groups.

Table 1: Distribution of the patients by age $(n=40)$

\begin{tabular}{|l|c|c|c|}
\hline \multirow{2}{*}{ Age (years) } & \multicolumn{2}{|c|}{ Group } & \multirow{2}{*}{ p value } \\
\cline { 2 - 3 } & $\begin{array}{c}\text { Endoscope -assisted } \\
\text { group }(\mathbf{n = 2 0})\end{array}$ & $\begin{array}{c}\text { Craniotomy group } \\
(\mathbf{n = 2 0})\end{array}$ & \\
\hline$\leq 40$ & $1(5.0)$ & $3(15.0)$ & \\
\hline $41-50$ & $4(20.0)$ & $9(45.0)$ & \\
\hline $51-60$ & $9(45.0)$ & $3(15.0)$ & $0.110^{\text {ns }}$ \\
\hline$>60$ & $6(30.0)$ & $5(25.0)$ & \\
\hline Total & $20(100.0)$ & $20(100.0)$ & \\
\hline Mean \pm SD & $57.9 \pm 9.9$ & $52.2 \pm 11.7$ & \\
\hline Range (min=max) & $34-75$ & $35-72$ & \\
\hline
\end{tabular}

Table 2: Distribution of study population according to gender in both groups $(n=40)$

\begin{tabular}{|l|c|c|c|}
\hline \multirow{2}{*}{ Gender } & \multicolumn{2}{|c|}{ Group } & \multirow{2}{*}{ p value } \\
\cline { 2 - 3 } & $\begin{array}{c}\text { Endoscope- assisted } \\
\text { group }(\mathbf{n = 2 0})\end{array}$ & $\begin{array}{c}\text { Craniotomy group } \\
(\mathbf{n = 2 0})\end{array}$ & \\
\hline Male & $15(75.0)$ & $16(80.0)$ & $0.705^{\text {ns }}$ \\
\hline Female & $5(25.0)$ & $4(20.0)$ & \\
\hline Total & $20(100.0)$ & $20(100.0)$ & \\
\hline
\end{tabular}

Table 3: Distribution of patients by GCS in both groups

\begin{tabular}{|c|l|l|l|}
\hline \multirow{2}{*}{ GCS } & \multicolumn{2}{|l|}{ Group } & \multirow{2}{*}{ p value } \\
\cline { 2 - 3 } & $\begin{array}{l}\text { Endoscope assisted } \\
\text { group }\end{array}$ & Craniotomy & \\
\hline Pre operative GCS & & & \\
\hline $8-10$ & $19(95.0)$ & $18(90.0)$ & 0.548 \\
\hline $11-13$ & $1(5.0)$ & $2(10.0)$ & \\
\hline GCS on $3^{\text {rd }}$ POD & & & 0.476 \\
\hline$<8$ & $2(10.0)$ & $2(11.8)$ & \\
\hline $8-10$ & $5(25.0)$ & $5(29.4)$ & \\
\hline $11-13$ & $8(40.0)$ & $9(52.9)$ & \\
\hline$>13$ & $5(25.0)$ & $1(5.9)$ & \\
\hline GCS on discharge & & & \\
\hline 10 & $1(6.3)$ & 0.0 & \\
\hline $11-13$ & $5(31.3)$ & $8(61.5)$ & \\
\hline & $10(62.5)$ & $5(38.5)$ & \\
\hline
\end{tabular}


Table 4: Duration of operating time in hours in both groups $(n=40)$

\begin{tabular}{|l|c|c|c|}
\hline \multirow{2}{*}{$\begin{array}{l}\text { Duration of } \\
\text { operation (hours) }\end{array}$} & \multicolumn{2}{|c|}{ Group } & \multirow{2}{*}{ value } \\
\cline { 2 - 3 } & $\begin{array}{c}\text { Endoscope assisted } \\
\text { group (n=20) }\end{array}$ & $\begin{array}{c}\text { Craniotomy group } \\
(\mathbf{n}=\mathbf{2 0})\end{array}$ & \\
\hline Mean \pm SD & $1.23 \pm 0.47$ & $2.15 \pm 0.56$ & $<0.001^{\text {s }}$ \\
\hline Range (min - max) & $0.5-2.0$ & $1.0-3.0$ & \\
\hline
\end{tabular}

Table 5: Distribution of patients by pre- operative CT scan findings

\begin{tabular}{|c|c|c|c|}
\hline \multirow{2}{*}{ Pre operative CT findings } & \multicolumn{2}{|c|}{ Group } & \multirow{2}{*}{ v value } \\
\cline { 2 - 3 } & $\begin{array}{c}\text { Endoscope assisted } \\
\text { group (n=20) }\end{array}$ & $\begin{array}{c}\text { Craniotomy } \\
(\mathbf{n = 2 0})\end{array}$ & \\
\hline Site of hematoma & & & \\
\hline Right & $8(40.0)$ & $8(40.0)$ & $1.000^{\text {ns }}$ \\
\hline Left & $12(60.0)$ & $12(60.0)$ & \\
\hline Location of hematoma & & & \\
\hline Ganglio-thalamic & $9(45.0)$ & $8(40.0)$ & $0.855^{\text {ns }}$ \\
\hline Lobar & & & \\
\hline Frontal-parietal & $2(10.0)$ & $2(10.0)$ & \\
\hline Parieto-temporal & $2(10.0)$ & $3(15.0)$ & \\
\hline Parietal & $6(30.0)$ & $7(35.0)$ & \\
\hline Occipital & $1(5.0)$ & $0(0.0)$ & \\
\hline
\end{tabular}

Surgical operating time is significantly shorter in endoscope-assisted group than craniotomy. Mean time is $1.23(0.47) \mathrm{hrs}$ in endoscope-assisted group and 2.15(0.56) hrs in craniotomy group. There is statistically significant difference in two groups regarding operating time $(\mathrm{p}<0.001)$. Majority of study patients in both groups had hematoma on left side. Hematoma was located in gangliothalamic region in $9(45 \%)$ patients in endoscope-assisted group and $8(40 \%)$ patients in craniotomy group. No significant difference was observed ( $p>0.05$ ) [Tables 4 and 5].

Table 6 shows evacuation of hematoma is better in endoscope-assisted group than craniotomy group. There is significant difference in postoperative volume in both groups $(\mathrm{p}<0.05)$. Table 7 shows hematoma evacuation rate in both groups. Mean evacuation is 74(11) \% in endoscope-assisted group and 65(13) \% in craniotomy group. There is statistically significant difference between two groups regarding hematoma evacuation rate $(\mathrm{p}<0.05)$. It was calculated from the formula that utilizes preoperative and post-operative hematoma volume. Table 8 shows four patients died from endoscopeassisted group (20\%) and seven patients died from craniotomy group (35\%) There was no significant difference in two groups $(\mathrm{p}>0.05)$ regarding mortality between two groups.

Table 6: Pre operative and post operative hematoma volume in both groups

\begin{tabular}{|l|c|c|c|}
\hline Hematoma volume $(\mathbf{m l})$ & \multicolumn{2}{|c|}{ Group } & \multirow{2}{*}{$\begin{array}{c}\text { p value (between } \\
\text { groups) }\end{array}$} \\
\cline { 2 - 3 } & $\begin{array}{c}\text { Endoscope assisted } \\
\text { group }(\mathbf{n = 2 0})\end{array}$ & $\begin{array}{c}\text { Craniotomy } \\
(\mathbf{n = 2 0})\end{array}$ & \\
\hline Pre operative & $46 \pm 8$ & $47 \pm 8$ & $0.697^{\mathrm{ns}}$ \\
\hline Post operative & $12 \pm 5$ & $17 \pm 7$ & $0.025^{\mathrm{s}}$ \\
\hline
\end{tabular}

Table 7: Hematoma evacuation rate in both groups $(n=40)$

\begin{tabular}{|l|c|c|c|}
\hline \multirow{2}{*}{ Hematoma evacuation rate (\%) } & \multicolumn{2}{|c|}{ Group } & \multirow{2}{*}{ p value } \\
\cline { 2 - 3 } & $\begin{array}{c}\text { Endoscope assisted } \\
\text { group }(\mathbf{n = 2 0})\end{array}$ & $\begin{array}{c}\text { Craniotomy } \\
(\mathbf{n = 2 0})\end{array}$ & \\
\hline Mean \pm SD & $74 \pm 11$ & $65 \pm 13$ & $0.036^{\mathrm{s}}$ \\
\hline Range $(\min -\max )$ & $55-89$ & $30-87$ & \\
\hline
\end{tabular}


Table 8: Distribution of study population according to mortality in both groups $(n=40)$

\begin{tabular}{|l|c|c|c|}
\hline \multirow{2}{*}{ Mortality } & \multicolumn{2}{|c|}{ Group } & \multirow{2}{*}{ p value } \\
\cline { 2 - 3 } & $\begin{array}{c}\text { Endoscope assisted } \\
\text { group (n=20) }\end{array}$ & $\begin{array}{c}\text { Craniotomy } \\
(\mathbf{n = 2 0})\end{array}$ & \\
\hline Present & $4(20.0)$ & $7(35.0)$ & \\
\hline Absent & $16(80.0)$ & $13(65.0)$ & $0.288^{\text {ns }}$ \\
\hline
\end{tabular}

Table 9: Distribution of patients according to mRS in 3 months follow up

\begin{tabular}{|l|c|c|c|}
\hline \multirow{2}{*}{ mRS } & \multicolumn{2}{|c|}{ Group } & p value \\
\cline { 2 - 3 } & $\begin{array}{c}\text { Endoscope assisted group } \\
(\mathbf{n = 1 6})\end{array}$ & $\begin{array}{c}\text { Craniotomy } \\
(\mathbf{n = 1 3})\end{array}$ & \\
\hline No symptoms & $6(37.5)$ & $2(15.3)$ & \\
\hline No significant disability despite symptoms & $4(25.0)$ & $1(7.7)$ & $0.034^{\mathrm{s}}$ \\
\hline Slight disability & $6(37.5)$ & $5(38.5)$ & \\
\hline Moderate disability & $0(0.0)$ & $5(38.5)$ & \\
\hline
\end{tabular}

Distribution of patients according to modified Rankin Scale (mRS) at 3- months follow up. Moderate disability of $\mathrm{mRS}$ scale was more frequent in craniotomy group $(38.5 \%)$ that is absent in endoscope-assisted group. A good number of patients (10) had no symptoms and no significant disability despite symptoms in endoscope-assisted group. There is statistically significant difference regarding outcome in both groups $(\mathrm{p}<0.05)$ [Table 9].

\section{Discussions}

Analysis of age distribution showed mean (SD) age of endoscope-assisted group and craniotomy group were found 57.9(9.9) and 52.2(11.7) years respectively. There were a good number of patients between 51 to 60 years age group in endoscopy group and 41 to 50 years age group in craniotomy group. A study done by Ibrahim (2016) observed mean age of the patient was 56.5 years in the endoscopic group and 51.4 years in the craniotomy group ${ }^{[16]}$, which is comparable with the current study.

Male sex was found predominant in both group .The distribution of male was $75 \%$ and $80 \%$ in endoscope-assisted and craniotomy group respectively. Zhang et al. $2014^{[17]}$ conducted a study in 51 patients divided in endoscopy group (21) and craniotomy (30) group, of them total 38 was male and 13 was female that was not statistically significant.
In our study hematoma was located in gangliothalamic region in $9(45 \%)$ patients in endoscopeassisted group and $8(40 \%)$ patients in craniotomy group. Parietal ICH was present in $6(30 \%)$ in endoscope-assisted group and $7(35 \%)$ in craniotomy group. Ibrahim (2016) observed in his study: in 13 patients hematoma was lobar (parietal lobe) in endoscopic group and it was in 11 patients in craniotomy group. ${ }^{[16]}$

In this study, GCS on admission was 8-10 in $19(95 \%)$ patients and $11-13$ in $1(5 \%)$ patient in endoscope-assisted group.GCS was $8-10$ in $18(90 \%)$ patients and $11-13$ in $2(10 \%)$ in craniotomy group. In 3rd post-operative day GCS improved to $11-13$ in $8(40 \%)$ patients and $>13$ in $5(25 \%)$ patients and deteriorate in 2 patients in endoscope-assisted group. In craniotomy group GCS improved to $11-13$ in $9(52.9 \%)$ patients, $>13$ in $1(5.9 \%)$ patients and deteriorate in 2 patients. Wang et al .2015 observed that the median preoperative GCS score was 8 and median GCS score 1 week after surgery was $11 .^{[13]}$ In this study 3 patients died from craniotomy group before 3rd post-operative day. At discharge 10(62.5\%) patients from endoscopy group found to be a GCS score $>13$ and $5(38.5 \%)$ patient from craniotomy group had the GCS $>13$. Four patients from endoscope-assisted group and anther four patients from craniotomy group died before discharge. Mean pre-operative hematoma volume was $46 \pm 8$ $\mathrm{ml}$ in endoscopy group and $47 \pm 8 \mathrm{ml}$ in craniotomy group. Hematoma evacuation rate was 
$74 \pm 11 \%$ in endoscope-assisted group and $65 \pm$ $13 \%$ in craniotomy group. There is statistically significant difference between two groups $(\mathrm{p}<0.05)$. Ibrahim (2016) observed median preoperative volume was $56.8 \mathrm{ml}$ in endoscopic group and $64.83 \mathrm{ml}$ in craniotomy group. ${ }^{[16]}$

Mean operating time was 1.23(0.47) hrs in endoscope-assisted group and 2.15(0.56) hrs in craniotomy group. There was statistically significant difference between two groups $(p<0.05)$. In a study by Zhang et al .2014 operating time was $76.48 \pm 14.92 \mathrm{~min}$ in the neuroendoscopy group, significantly shorter than $175 \pm 26.13 \mathrm{~min}$ in the craniotomy group $(\mathrm{p}<0.00001){ }^{[17]}$

In our study 4 patients died from endoscopeassisted group (20\%) and 7 patients died from craniotomy group (35\%). Ibrahim (2016) observed that mortality rates were $36.8 \%$ for the endoscopy group and $63.2 \%$ for the craniotomy group which was statistically significant $(\mathrm{p}<0.05){ }^{[16]}$

In our study $6(37.5 \%)$ patients had no symptoms (mRS-0), 4 (25\%) patients had no significant disability despite symptoms (mRS- 1), 6(37.5\%) had slight disability (mRS- 2) in endoscope assisted group. In craniotomy group 2 (15.3\%)) patients had mRS score $-0,1(7.7 \%)$ ) patients had mRS score $1,5(38.5 \%)$ had mRS score 2 and $5(38.5 \%)$ patients had mRS score 3. No patient found to develop moderate severe disability and severe disability in both groups. There is statistically significant difference in outcome in both groups $(\mathrm{p}<0.05)$. Zhang et al. 2014 observed no statistically significant difference in $\mathrm{mRS}$ in endoscopy $(3.57 \pm 1.66)$ and craniotomy $(3.88 \pm 2.14)$ group $(\mathrm{p}=0.56)^{17}$.

\section{Conclusion}

This study revealed that hematoma evacuation rate was better in endoscope-assisted group and had less operating time than craniotomy. Outcome is better in endoscope-assisted group than in craniotomy group. In this study there is no statistically significant difference between two groups regarding age, sex, improvement of GCS and mortality rate. Endoscope-assisted hematoma evacuation may be a promising minimally invasive technique in spontaneous intracerebral hematoma.

\section{References}

1. Reichart R. and Frank S. Intracerebral Hemorrhage, Indication for Surgical Treatment and Surgical Techniques. The Open Critical Care Medicine Journal 2011; 4: 68-71.

2. Siddique M.S and Mendelow A.D. Surgical treatment of intracranial hemorrhage. British Medical Bulletin 2000; 56(2): 444-456.

3. Elijovich L, Pratik VP and Hemphill JC. Intracerebral Hemorrhage. Semin Neurol 2008; 28: 657-667.

4. Ropper AH and Davis KR. Lobar cerebral Hemorrhages: Acute Clinical Syndromes in 26 cases. Ann Neurol 1980; 8: 141-147.

5. Sonni S, Lioutas VA and Selim MH. New avenues for treatment of intracranial hemorrhage. Curr Treat Cardiovasc Med 2014; 16(1): 277.

6. Magistris F, Bazak S and Martin J. Intracerebral Hemorrhage: Pathophysiology, diagnosis and management. MUMJ 2013; 10(1): 15-22.

7. Juvela S, Heiskanen O, Poranen A, Valtonen S, Kuurne T, Kaste M. and Troupp H.) The treatment of spontaneous intracerebral hemorrhage . J Neurosurg 1989; 70: 755-758.

8. Dey M, Stadrik A and Awad IA. Spontaneous Intracerebral and Intraventricular Hemorrhage: Advances in Minimally Invasive Surgery and Thrombolytic Evacuation, and Lessons Learned in Recent Trials. Congress of Neurological Surgeons 2014; 74 (2): 142150.

9. Kim HT, Lee JM, Koh EJ and Choi HY. Surgery versus Conservative Treatment for 
Spontaneous Supratentorial Intracerebral

Hemorrhage in Spot Sign Positive Patients. J Korean Neurosurg Soc 2015; 58(4): 309-315.

10. Kuo LT, Chen CM, Li CH, Tsai JC, Chiu HC, Liu LC, Tu YK and Huang AP. Early endoscopic-assisted hematoma evacuation in patients with supratentorial intracerebral hemorrhages: case selection, surgical technique, and long-term results. Neurosurg Focus 2011; 30(4): 1-8.

11. Romero FR, Zanini MA, Ducatti LG. and Gabarra R.C. Spontaneous intracerebral hemorrhage treated by neuroendoscopy Technical note. Arq Bras Neurocin 2013; 32(1): 26-30.

12. Kothari RU, Brott T, Broderick JP, Barsan WG, Sauerbeck LR, Zuccarello M, Khoury J. The ABCs of measuring intracerebral hemorrhage volumes. Stroke; a journal of cerebral circulation 1996; 27: 1304-1305.

13. Wang WH, Hung YC, Hsu SP, Lin FC, Chen HH, Shin $\mathrm{YH}$ and Lee CC).Endoscopic hematoma evacuation in patients with spontaneous supratentorial intracerebral hemorrhage. Journal of the Chinese Medical Association 2015; 78: 101-107.

14. Hsieh PC, Cho DY, Lee WY, Chen JT. Endoscopic evacuation of putaminal hemorrhage: how to improve the efficiency of hematoma evacuation. Surg Neurol 2005; 64:147-153.

15. Bakshi A., Bakshi AD and Banerji AK. Neuroendoscope-assisted evacuation of large intracerebral hematomas: introduction of a new, minimally invasive technique. Neurosurg Focus 2004; 16(6): $1-5$.
16. Ibrahim,

A.

Comparison

between Modified Neuroendoscopy and Craniotomy Evacuation of Spontaneous Intra-Cerebral Hemorrhages: Study of Clinical Outcome and Glasgow Outcome Score. Bali Medical Journal 2016; 5(1): 86-91.

17. Zhang HZ, Li YP, Yan ZC, Wang XD, She L. Endoscopic Evacuation of Basal Ganglia Hemorrhage via Keyhole Approach Using an Adjustable Cannula in Comparison with Craniotomy. Bio Med Research International; 2014:1-6.

18. Morgenstern LB, Hemphill JC 3rd, Anderson C, Becker K, Broderick JP, Connolly ES Jr, Greenberg SM, Huang JN, MacDonald RL, Messe SR. (2010) Guidelines for the management of spontaneous intracerebral hemorrhage: a guideline for healthcare professionals from the American Heart Association/American Stroke Association. Stroke; a journal of cerebral circulation: 2010; 41: 2108-2129. 